\title{
El Indio Boliviano y la Colonia
}

El origen de los indios. - El testamento de Isabel la Católica. - Las Casas y Seprilveda. - Las Leyes de Indias. - Las Ordenanzas del Virrey Toledo. - Las Ordenanzas del Visitador Alfaro. - El contenido social y económico de la situación de los indios en el Alto Perú.

$\mathrm{F}^{\mathrm{L}}$ descubrimiento de las tierras de América, al abrir un nuevo escenario geográfico al mundo europeo del Renacimiento, planteó el problema más inquietante a la mente de la época, o sea el origen de los indios, y si éstos eran hombres o pertenecían a una especie zoológica pariente de las alimañas y de las bestias.

Dado el clima intelectual renacentista, las explicaciones que se encontraron fueron naturalmente de orden teológico. La Biblia fué el más importante documento de información sobre el origen de los indios, y el Antiguo Testamento constituyó el refugio mental para las explicaciones del más profundo de los interrogantes de la humanidad de todos los tiempos. Los sabios y los teólogos se preguntaban aterrados: ¿ De dónde habían surgido los habitantes de las Indias? Y luego, como para consolarse de que no fuese herida la Biblia, sostenían que los habitantes de las tierras descubiertas no eran hombres. Anotemos las más pintorescas de estas disquisiciones. El teólogo Juan de Sepúlveda llegó a sostener, con abundantes razones, que los indios, estando más cerca de la barbarie que los hombres civilizados, no podían ser incluídos en el reino humano, estimando que pertenecían a la categoría de las bestias. Frente a Sepúlveda, en defensa de la racionalidad de los aborigenes, se situaron el Padre Acosta, Las Casas, Calancha y otros menos importantes. La disputa teológica prosiguió hasta que el Papa Paulo III 
decretó que los indígenas que vivían en las tierras descubiertas, descendían de Adán y Eva. La bula papal resolvió el problema en su doble significado: fijaba el origen del hombre americano y lo ungía contra los teólogos, dándole rango de pertenecer a la familia del rey de la creación. Pero la disputa no está resuelta del todo, porque surgió el nuevo problema relativo a la inferioridad y la esclavitud de los indios. La controversia salió del ámbito español y apasionó al mundo. Montaigne fué uno de los primeros en pronunciarse a favor de los indios, considerándolos como hombres normales en cuyo corazón se habían alojado las supremas virtudes de la bondad. El buen salvaje - lo que fué también para Voltaire en su drama famoso-, es un descendiente inmediato del autor de los Ensayos. Paracelso, en cambio, protestó, sosteniendo que los indios no "podían ser hijos de Adán y de la misma sangre y de la misma carne que los otros".

Sentado ya por el Papa que los indios eran de origen adámico, prosiguió el interés de probar la inferioridad de éstos, y así se les asimiló al origen judío y semita. El Padre Gregorio García, del siglo xvir, prueba que los indios son descendientes de los judíos, "porque éstos, como aquéllos, son perezosos, no creen en los milagros de Jesucristo y no están agradecidos a los españoles por todo el bien que les han hecho!" Pero, las pruebas sobre el judaísmo de los indios son mucho más humorísticas. Alguno de los teólogos afirmó que invirtiendo la $\mathrm{N}$ de la palabra indio se convierte en $\mathrm{U}$, leyéndose iUdio en lugar de INDio, y que ésta era la prueba del semitismo de los aborígenes. Frente a tan quiméricas apreciaciones que sólo tendían a satisfacer los derechos de colonización y de dominio de los españoles, también se sostuvieron ideas que al enaltecer el origen de los indios, al probar su elevada alcurnia, tendian también a situar a mayor altura a los propios españoles. Diego Andrés Rocha se empeñó en demostrar que los indios americanos descendían de la raza ibera del tiempo de Osiris, Tabul y Hespero, Esta posición de entroncar a los indios con los iberos, parientes inmediatos de los conquistadores, era una forma de negar la inferioridad racial de los aborígenes, que algunos con tanto ardor se empeñaban en defender. E1 Padre Acosta, siempre ecuánime, busca una postura intermedia y sostiene "que cuando cesó el diluvio, del Arca de Noé salieron las parejas allí encerradas, donde la vida les era fácil y posible, abandonando por completo el antiguo Continente y pasando al Nuevo por Tierras Articas". El Padre Calancha, con una ten- 
dencia más amplia y que fué sostenida por algunos autores del siglo xIX que han conciliado el monogenismo con el poligenismo, propugna que después del Diluvio la humanidad se esparció por la tierra, dejando avizorar que la Atlántida había sido el puente por el cual pasaron los hombres del viejo Mundo a las tierras colombinas.

Así, pues, los indios son hombres, por tanto tienen alma y merecen, como hijos de Dios, ser cristianos y protegidos por la Iglesia, pero no directamente por ella, sino a través de los Reyes Católicos. E1 testamento de Isabel la Católica contiene en este sentido la doctrina política y cristiana que inspiró la conducta de España con relación a los indios: "Suplico -dice- al Rey mi Señor muy afectuosamente y encargo y mando a la princesa mi hija y al príncipe mi marido que así lo hagan y cumplan, y que éste sea su principal fin, y en ello pongan mucha diligencia y no consientan ni den lugar a que los indios vecinos y moradores de dichas islas y Tierra Firme, ganados y por ganar, reciban agravio alguno en sus personas $y$ bienes, mas manden que sean bien y justamente tratados, $y$ si algún agravio han recibido, lo remedien y provean de manera que no se exceda cosa alguna lo que por las letras apostólicas de dicha concesión nos es inyungido y mandado." No pueden ser más piadosos, ni más altruístas ni caritativos los deseos de la Reina Conquistadora. La ejecución de este testamento habría sido suficiente doctrina, voluntad de poder, para gobernar a los indios de las colonias hispanas y derramar sobre ellos los bienes de la libertad humana y los derechos primarios inherentes al respeto de la integridad humana y de la dignidad del hombre. Analicemos rápidamente cómo se cumplió el testamento de Isabel la Católica, a través de la más grande polémica del siglo xvis relativa a los indios, stustentada por Juan de Sepúlveda y Fray Bartolomé de las Casas. Estas disquisiciones -aparte del interés documental que dan el matiz al color del tiempo- también nos demuestran que tras de ellas se movían grandes intereses económicos. Los indios fueron para los teólogos españoles motivo de meditación metafísica, de construcción teológica, de estructura razonadora, que afectaron a la moral, al derecho privado y al derecho internacional.

La antinomia Las Casas-Sepúlveda no ha desaparecido; por eso es sugestivo stu examen, porque aún divide a las mentalidades en clásicos y románticos, en conservadores y liberales, en derechas e izquierdas, en católicos y agnósticos. Se trata de un duelo intelectual 
librado no entre dos hombres, sino entre dos expresiones permanentes del pensamiento humano, que a lo largo de la historia afectan distintas corrientes, pero que representan la eternidad de los intereses y de las pasiones del hombre. Es la lucha entre la libertad y la opresión, entre la barbarie y la dignidad, entre la razón y las pasiones, en suma, entre el derecho y la fuerza. El derecho puesto al servicio de los humildes y de los indefensos, y la fuerza tras la cual se esconden la codicia y el sensualismo del mando. Hay un momento de perplejidad mental, cuando nos situamos en una posición equidistante y objetiva frente a las doctrinas de Sepúlveda y de Las Casas. A las dos es necesario juzgarlas sumergidas en el agua de su tiempo, porque el instrumentarlas con el contrapunto de músicas actuales o del siglo xix, constituiría un error de perspectiva histórica.

Sepúlveda considera a los indios un pueblo inferior física y mentalmente, cree en la existencia de las razas aristocráticas y superiores y es actuando dentro de este círculo como su idea matriz cree en la licitud de hacer la guerra a los gentiles, para obligarles a recibir el evangelio, "tomándoles cuanto el derecho de la guerra permite"; considera que los pueblos idólatras (inferiores) no tienen derecho de resistir a los pueblos cristianos (superiores), postulando que si el pueblo idólatra resiste, es lícita la guerra hasta el exterminio, y por último dogmatiza que siendo los indios de América hombres, pero no siervos a natura, "lo perfecto debe imperar sobre lo imperfecto, lo excelente sobre lo contrario, los indios deben estar sujetos a un régimen de sumisión sobre los cristianos". La tesis de Sepúlveda, humanista aunque no humanitario, está basada en la Biblia y en la doctrina del Estagirita. La esclavitud que no estremece a Aristóteles también está grabada en el Pentateuco.

La doctrina del Padre Las Casas se inspira en el cristianismo, en la caridad católica, en la fe de una humanidad mejor y en el idealismo de salvar a los hombres para la religión del Crucificado, arrancándolos de las garras de la codicia. Esta doctrina puede resumirse en los siguientes puntos básicos: Que era preciso tolerar la idolatría entre los indios por su muchedumbre y porque siempre habian sido idólatras; que los soberanos de América tienen jurisdicción sobre. sus propios súbditos y que eran tan independientes de los soberanos católicos que ningún derecho tenían éstos como tales sobre aquéllos; que si un soberano católico tiene súbditos idólatras, el príncipe debe tolerar la idolatría, siempre que de la intolerancia no pueda surgir 
mal grave, escándalo, ruinas, guerras y hasta impedimento de que vengan paulatinamente a la fe algunos de ellos; que los reyes no son señores de sus estados, ni dueños de las vidas de sus súbditos; que Jesucristo mandó a sus apóstoles y a la Iglesia predicar pacíficamente la remisión de los pecados, ya que con el bautismo se perdonan todas las culpas, pero no impone castigo alguno a los pecados anteriores, y, finalmente, que los indios de América, siendo hombres y no siervos por naturaleza, no deben estar sujetos a un régimen de sumisión.

Como integrante de la doctrina del Padre Las Casas, es necesario citar la concepción jurídica del derecho de gentes del Padre Vitoria, quien planteó la inasistencia de derecho a los españoles para emprender la obra de la Conquista, buscando la necesidad de justificarla. “¿Por qué leyes - dice-vienen los indios a poder de los españoles? ¿Cuáles son las bases y los límites del poder del monarca sobre los pueblos de las nuevas tierras en lo civil y en lo temporal? ¿Y la iglesia en materia religiosa qué đerechos tiene espiritualmente sobre los indios?" No cree el Padre Vitoria que "las leyes divinas puedan tener dominio sobre los indios, porque los indios como todos los hombres están sometidos a las leyes divinas". Es con esta fórmula verdaderamente demoledora con la que el Padre Vitoria sitúa la justicia y el derecho por encima de la autoridad espiritual del Papa y de la autoridad temporal del Rey, de tal modo que ninguno de estos poderes puede someter a su dominio a los indios, que son libres y sujetos a su propia potestad. Doctrina anárquica frente a los dos imperialismos del momento histórico, sustentada con grave peligro en el siglo xvr. De esta tesis parte Vitoria, creyendo en el no sometimiento de los pueblos y en la doctrina de la libre asociación de los soberanos. Así, pues, Vitoria habría soñado que el imperio de los Incas hubiese llegado a integrar una sociedad politica con España con iguales derechos y deberes. Resulta, pues, el Sócrates alavés un precursor del sistema del Imperio Británico y de la Sociedad de las Naciones. El Padre Las Casas y el Padre Vitoria se confunden en el espíritu, para ser contemplados en un solo abrazo de luz.

Las posiciones opuestas, irreductibles, de Las Casas y Sepúlveda no tienen puntos de contacto, capaces de llevar su pensamiento al vértice de la conciliación. La doctrina de Las Casas es una tendencia política que importa un método de gobierno. Es una idea de 
igualdad humana ante Dios, que sirve de instrumento estatal, para el gobierno de los hombres de una Colonia. Hay en el pensamiento de Las Casas un soplo de intención económica, de reivindicaciones del hombre despojado hacia el conquistador y un contenido de filantropía y altruísmo, sin el significado comptiano de estas palabras, pero con la expresión de caridad y de humildad cristianas. Se ha acusado a Las Casas como a uno de los creadores de la llamada leyenda negra española, pero nunca se ha dicho que Ginés de Sepúlveda fué el reivindicador de España. Las Casas es el pensamiento de una España soñadora, idealista, humana. Las Casas es el caballero del cisne de aquella danza de apetitos y es el apóstol de las Indias. Sepúlveda es la voluntad de España imperial, afiebrada de pasión, apegada a la realidad, que osa a la tierra baja. Ambas son la eterna España, el delirio de don Quijote y la alegría sanchuna. Las Casas y Sepúlveda encarnan las dos grandes fuerzas de la historia. El pensamiento y la pasión. El pensamiento es el material decorativo de la historia, mientras que la pasión es la realidad palpitante. La historia vivida al calor del pensamiento de los sabios y de los utopistas, sería un poema de gloria, mientras que la historia escrita con la sangre de la pasión es la historia vivida. Si 1a historia de la conquista se hubiese realizado bajo la sombra predilecta de Las Casas, las colonias de América las hubiéramos podido contemplar como un gigantesco falansterio, situado en la isla de la Utopia; pero la conquista se ha cumplido bajo el signo de la espada y de la cruz de Ginés de Sepúlveda y fué hecha por hombres que convirtieron a la América, con la dominación colonial, en una tierra de hombres a imagen y semejanza de los de España, con todos sus defectos y con todas sus virtudes.

Al influjo de las prédicas del Padre Las Casas, de su afán evangelizador, de su fervor combativo contra los españoles y a favor de los indios, surgieron las Leyes de Indias, a cuyo espiritu no fueron ajenos los teólogos Vitoria, Soto, Bernardino Minaya. Esta España con las Leyes de Indias construyó tuno de los monumentos jurídicos más vigorosos de la humanidad, quedando como expresiones del derecho complementarios al derecho romano. El espíritu jurídico de las Leyes de Indias está unido a la fuerza moral y religiosa. Tiene la complejidad de un texto bíblico en el que se legisla y se dan normas de ética o prescripciones higiénicas al lado de disposiciones de regulación económica o social. Hay en estas leyes 
que admirar el vigor de la lógica jurídica, la inflexibilidad de la razón práctica, un temperamento de minuciosa previsión y el afán de vaciar en la fórmula legal un contenido al mismo tiempo episódico y de eternidad. Los juristas que redactaron las Leyes de Indias hasta dando instrucciones a las autoridades sobre el uso adecuado y propio de los vocablos, parecen vivir en una atmósfera de formas geométricas, en un perpetuo éxtasis surrealista de las formas ideales y de un delirio de la razón. No es que estos juristas sean hombres desdeñosos de la realidad, sino que son mentes enamoradas de la perfección; no practican una política pragmática, sino una política de principios idealistas. Son unos fervorosos de la razón aristotélica que van delante de las huestes religiosas, y tienen, como los místicos, el culto a una perfección quimérica que se sublima en la idea de Dios, la suprema perfección geométrica. Por esto, el defecto de las Leyes de Indias es que son demasiado perfectas.

Vamos a clasificar las Leyes de Indias en lo relativo a la Legislación de los naturales como sujetos de derecho público:

Del principio de igualdad y libertad.-Los indios no son iguales ante la ley, gozan de privilegios. Existen abogados protectores de indios, que están supervigilados por las autoridades. Estos protectores de indios no pueden ser mestizos, "porque así conviene a su defensa y de lo contrario se les puede seguir daño y perjuicio". En 1a Audiencia de Charcas no hay indios esclavos, los indios son libres y no están sujetos a servidumbre. No puede hacerse el tráfico de indios, castigándose a los encomenderos que vendieran sus indios. El esclavo indio que pisaba territorio de los dominios españoles, automáticamente recobraba su libertad. Para garantizar la libertad de los indios se disponía que fueran favorecidos y amparados por las justicias eclesiásticas y seculares, que pudieran "ser puestas en policía sin ser oprimidos". Pero, al mismo tiempo, también se prohibía pintorescamente que los indios viajasen a caballo!

Las leyes relativas a la protección que debían prestar a los indios los curas y doctrineros son innumerables, pero citaremos entre ellas las principales, la relativa a que los doctrineros sepan lengua de los indios, que los clérigos y religiosos no prendan ni hagan condenaciones a los indios, ni nombren fiscales, cumpliendo los aranceles y que los indios no sean apremiados a ofrecer en las misas. 
Para hacer efectiva esta protección de los indios, la ley establecía. que proceda contra los ministros que carguen indios o les quitaren sus haciendas o mujeres, y que ningún mestizo que no sea hijo, legítimo o vecino pueda cargar indios en los casos permitidos.

Derecho de asociación.-Los indios podían asociarse para formar gremios. Para ello tenían que pedir permiso a las autoridades eclesiásticas, de actuerdo al régimen interno de la constitución de gremios.

Derecho de petición.-Los indios, por privilegio especial, tenían algo así como un derecho de petición, pues podían dirigirse sin más. trámites al Rey, para formular quejas y solicitudes. Además, los indios gozaban del privilegio de prioridad, para las audiencias del virrey y del presidente de la Audiencia, a cuyas cámaras podian ingresar sin pedir permiso.

Inviolabilidad del hogar-Aunque el concepto es propiamente el de garantizar la inviolabilidad del hogar, se prohibe con criterio policiario y de proteger a los indios, que los españoles vayan a "posar a casa de indios", alli donde no haya mesones. También se establece que ningún español "resida en pueblo de indios más del día que llegare u otro". Igualmente se limita con fines de garantizar el hogar que ningún mercader podía estar más de tres días en un pueblo. de indios.

Derecho de reunión.-En esta materia las Leyes de Indias no. consideran nada, permitiendo las reuniones para la asistencia de las. procesiones. Se les prohibe a los indígenas el uso de las armas.

Derecho de seguridad personal.-Las disposiciones de las Leyes de Indias garantizan la seguridad personal de los naturales en forma inversa a la de nuestros derechos actuales. Establecen que los indios pueden permanecer en cualquier punto y que "pueden mudar de unos lugares a otros", y prohibe que "los indios de tierras frías sean llevados a tierras calientes", y "que por ejemplo, los de Santa Cruz, no sean sacados para otras provincias, que los indios: no sean llevados a España y que los que estuvieren allí vuelvan pagando los gastos la Corona".

En otro sentido, la seguridad personal no está garantizada, pues existe la posibilidad del extrañamiento sin más trámites, y cuando se aplica como pena, es una de las más suaves y corrientes. 
Educación.-Se establece por término general, mediante el régimen de religiosos, curas y doctrineros, para los indios que deben ser cristianamente tratados administrándoseles los sacramentos y la enseñanza del catecismo. También se provee que "a los indios se les paguen maestros que enseñen a los que voluntariamente quieran aprender como les sea de menos molestia y sin costa, y ha parecido que éstos podrían ser los sacristanes como en las aldeas de estos reinos enseñan a leer y escribir y la doctrina cristiana".

Libertad de cultos.-Dada la mentalidad de la época, la única libertad que existía en materia religiosa, era la de elegir entre ser fraile y seglar. Los indios perdieron la libertad de creer en sus propias divinidades, obligándoseles, por todos los medios, a cristianizarse. Se les impone el cumplimiento de ritos y preceptos, así como la comunión antes de morir, so pena de poder testar. Igualmente se castigaba con penas severas a los hechiceros, se les perseguía y destruía sus ídolos, y el fervor proselitista era tan grande que una real cédula del 6 de marzo de 1687, dictamina que los indios que voluntariamente se conviertan al cristianismo quedan libres de tributos durante veinte años. Era un buen método de captación política.

No existió ni asomo de libertad de cultos, ni en los tiempos volterianos y masónicos de la ilustración del Conde de Aranda y de Carlos III.

Derechos sociales.-Existe en las Leyes de Indias una serie de disposiciones que vamos a clasificar entre las que hoy se conocen con el nombre de derechos sociales. Estas disposiciones se derivan del estado en que se encontraban los indigenas y obedecen al deseo de mejorar su condición humana. Entre estos derechos sociales anotaremos los relativos a la familia. Disponen que los indios se puedan casar libremente y que ninguna orden se lo impida con las limitaciones de que no se les permita el matrimonio sin tener edad legítima, y que los indios que se "casen con dos mujeres sean castigados". También se prescribe que la india casada sea del pueblo de su marido, y que estando viuda, pueda volver al sitio de su origen. Determinan, muy ingenuamente, que los indios no se olviden de sus padres y que éstos no los vendan para contraer matrimonio. Disponen que la india que tuviese hijos de español, puede mudar domicilio, y que los "indios puedan poner a sus hijos a oficio, mientras no tributen". 
En este mismo aspecto de acción social se pueden situar órdenes relativas a la conservación de la moral y de las buenas costumbres; así, por ejemplo, se dispone que los indios vayan vestidos, reglamentándose su indumentaria; se prohibe que los curas tengan sirvientas menores de cuarenta años; se les prohibe el juego a los indios, igualmente que las bebidas alcohólicas, y se "establece" que no se consientan bailes a los indios sin licencia del gobernador y "sea con templanza y honestidad".

Las ordenanzas del Virrey Toledo relativas a los derechos individuales y sociales de los indios, complementarias de las Leyes de Indias, cuya sintesis en líneas generales hemos hecho, las integramos ahora con un esquema de dichas principales ordenanzas.

Sobre el servicio de salubridad relativo a mantener el vigor de los indígenas, el Virrey Toledo dictó disposiciones sobre el trabajo de los naturales, la forma de aliviar sus enfermedades, y la asistencia en los hospitales, encontrándose a lo largo de sus prudentes disposiciones, algunas como las que prohiben que ningún español, mestizo o mulato, ni otro indio compre la comida de los indios; so pena de pagar veinte pesos de multa y destierro.

Para beneficio de los indios del Alto Perú dictó el Virrey Toledo una ordenanza relativa al método que se debe guardar, para entablar pleitos de los naturales y mediante la cual se regularizan los procedimientos que deberán seguir los defensores especiales de los aborígenes.

Otra ordenanza contiene previsiones acerca del procedimiento por el cual han de proveerse los mesones y las ventas de la provincia de Charcas.

La más importante de estas ordenanzas destinadas a los indios de la provincia de Charcas, es la que se refiere a "evitar daños y agravios que recibieren de sus encomenderos", determinando el modo de elección de alcaldes, la organización del cabildo indígena, la fórmula de testamento, cláusula de entierro y minas, herederos y albaceas, bienes de comunidad y obligaciones de los indios de cada pueblo. Estas ordenanzas detalladas, minuciosas y precisas, contienen, por ejemplo, determinaciones sobre la necesidad de que los indios se laven los pies y las manos, se corten el cabello y se hagan policía de las uñas. Imparte penas para los indios que tengan en sus casas parientes que no pasen de los cincuenta años; que los alguaciles hagan tocar la queda. Otras ordenanzas se refieren, por ejemplo, 
a que ningún indio podía ir vestido con un traje diferente al que le corresponde.

También legisló sobre enseñanza religiosa y la doctrina de los indios. "En cada pueblo - dice- debía haber una escuela, a la cual debían concurrir los indios a leer y escribir o hablar la lengua castellana como su magestad lo manda." Para ello debía procurarse un indio ladino y hábil, de que hay bastante número en todas partes, que sirva de maestro de escuela. El maestro lo nombraría el cura del pueblo y recibiría como salario todos los años dos vestidos de abasca, seis fanegas de maíz o cucho y doce carneros de Castilla. Los alumnos no deben ir a la escuela pasando de los trece a catorce años, para que puedan después ir a ayudar a sus padres. Los indios pastores deben ir al pueblo por turno, "para recabar los sacramentos".

Disponía como normas de vida y buenas costumbres "que los indios debían poner a sus hijos los nombres de sus padres y madres, abuelos, $y$ en ningún caso los de la luna, pájaros, animales, piedras, sierpes y ríos". Prohibió el juego de naipes entre los indios "que habían empezado a hacerse ociosos y olgazanes", aplicando al español, mestizo o mulato que jugare con los indios, multas, azotes y destierro.

Las Ordenanzas del Virrey Toledo tienen coordinación con las Ordenanzas del Visitador Alfaro, mediante las cuales este delegado de la Corona de España dictó una serie de previsiones articuladas con la finalidad de hacer efectivas la protección y defensa de los indios, para garantizarlos de los abusos de clérigos y encomenderos. Las Ordenanzas de Alfaro, en su esencia y muchas en su contenido, son nada más que una reiteración de las Leyes de Indias y de las Ordenanzas del Virrey Toledo. Por ejemplo, declaran que el servicio personal de los indios ha sido injusto contra todo derecho, prohibió la compraventa de indios, to mismo que éstos cambiasen de residencia, estableciéndose, casi con las mismas palabras que las Leyes de Indias, que "no deban ser trasladados de tierras calientes a tierras frías", etc. Reitera, dándole más fuerza a una ordenanza del Virrey Toledo mediante la cual se obliga a que los templos de los pueblos tuvieran puertas y llaves, "donde con decencia se celebre y pueda decir misa y haya de tener y tenga puerta con llave, para que no profanen ni entren animales en ella". Se repite que los indios tienen libertad de trabajar en las estancias y que las mujeres casadas debían vivir en los pueblos de maridos; igualmente se reitera que 
los indios puedan tener industria libre y libertad de contratarse. Contiene las mismas amonestaciones sobre el adoctrinamiento de los niños, que los curas deban conocer la lengua de los indios, y que debían ser gobernados por sus propios alcaldes y regidores, etc.

El punto capital de las Ordenanzas de Alfaro es el relativo a que "los indios de jornal deban cobrar sus sueldos cada semana $\mathrm{y}$ antes si el indio le pedía en sus propias manos en reales y no en especie, y si en vez de dinero se les daba vino, yerba o algarrobo, lo que en ansí se pague se les vuelva a pagar". Esta ordenanza, prescrita por las Leyes de Indias, tuvo valor porque trató de imponerse a los encomenderos y fué resistida por éstos. Bien a las claras se ve su tendencia dirigida a salvaguardar a los indios de las exacciones de que eran víctimas; pero los patrones alegaron que era a los propios indios a quienes no interesaba la medida.

La reacción contra las Ordenanzas de Alfaro se produjo no únicamente de parte de los encomenderos, sino de las autoridades civiles y eclesiásticas, con el mismo aparato y violencia que se opondrían hoy las gentes a un gobierno que dictara leyes atentatorias contra la propiedad. Se dice que el gran pecado de las Ordenanzas de Alfaro es el haberse adelantado a su tiempo y que su legislación fué revolucionaria e inadaptable al espíritu de la época. Lo que habría que añadir es que todas las Leyes de Indias corrieron la misma suerte que las Ordenanzas de Alfaro, que, como hemos indicado, no tuvieron ninguna originalidad, sino la de haber querido que ellas fueran una realidad consumada.

El rápido esbozo que se ha operado aquí de las Leyes de Indias, de las Ordenanzas del Virrey Toledo y de las Ordenanzas del Visitador Alfaro, en lo relativo a los derechos individuales o sociales del indio, nos permiten orientarnos sobre el temperamento de la legislación indiana. El cúmulo de disposiciones de carácter prohibitivo, que no es sino de oposición constante que se adelanta al interés; el carácter limitativo de las mismas y la minuciosidad con que se legisla, nos prueban dos cosas: primera y principal, que existió el exceso y la falta de respeto a la dignidad humana de los indios, y segundo, que tanto la Corona de España como sus agentes comprobaron esa iniquidad y trataron de ponerle coto y remedio, y por ello se legisló. Así, pues, el viejo pleito de la leyenda negra queda a nuestro juicio resuelto mediante un sentido de comprensión. La realidad de la miseria de los indios y la explotación de que fueron 
víctimas, sometidos a un trato brutal, limitrofe con la esclavitud, fué un hecho incuestionable, tan patente que todavía a ciento treinta años de la Colonia, en plena república democrática y liberal, no ha podido limpiarse la atmósfera en que vive el indio. La tradición de servidumbre del indio y la posición dominadora de los criollos y españoles no ha desaparecido, a pesar de los esfuerzos de buena voluntad contenidos en la legislación boliviana moderna, y de los ensayos pedagógicos y de servicio social. ¿Cómo pues, entonces, pensar que porque las Leyes de Indias fueron perfectas y las ordenanzas que se dictaron fueron prudentes y sabias, también fué humana y perfecta la condición de los españoles con relación al indio?

Lo que faltó a la legislación hispana de Indias fué que ella hubiese estado encarnada en la voluntad de mando. Si ella fué genial en su creación idealista, faltó en América un estadista de carácter que esculpiera en el mármol de la realidad esos sueños razonadores. Si se añade a esto la balumba de intereses, la pasión de enriquecimiento fácil y el orgullo español, frente al gregarismo indígena y a su falta de personalidad, no es difícil concebir que la Colonia fué una tragedia para el indio, como la época actual es todavía un drama.

\section{Gustavo Adolfo Otero,} La Paz. 
